\title{
Crashworthiness analysis and enhancement of aircraft structures under vertical impact scenarios
}

\author{
J. Paz *, J. Díaz ${ }^{\dagger}$, L. Romera \\ Structural Mechanics group, School of Civil Engineering, Universidade da Coruña, 15071 A Coruña, Spain
}

\begin{abstract}
This research focuses on the crashworthiness study and enhancement of commercial aircraft structures by developing crushable energy absorbers to work as vertical struts. To assess their contribution on a representative crash scenario, a numerical simulation of a Boeing 737-200 drop test developed and verified with experimental data is used as a benchmark. The numerical model is then enhanced with four hybrid energy absorbers designed for programmed and progressive collapse, added in the cargo compartment connecting the underfloor beams and the frames. These devices are composed of a square aluminum tube filled with a composite skeleton and foam extrusions for maximized energy absorption. The enhanced aircraft is later on simulated under hard landing and water ditching scenarios, analyzing the benefits resulting from the absorbers according to structural efficiency and biometric criteria. Results show increased plastic dissipation values by the main structural components given the modified collapse mechanism obtained when adding the crushable absorbers. Peak acceleration values are also reduced, consequently lessening the passenger injury prediction at the studied locations.
\end{abstract}

Nomenclature

$$
\begin{aligned}
& A=\text { Aluminum's yield stress } \\
& B=\text { Hardening law's amplitude modifier } \\
& C=\text { Strain rate's dependency modifier } \\
& p=\text { Equivalent plastic strain } \\
& \dot{p}=\text { Equivalent plastic strain rate } \\
& \dot{p_{0}}=\text { Reference equivalent plastic strain rate } \\
& \sigma_{\mathrm{y}}=\text { Tensile stress } \\
& E=\text { Young's modulus }
\end{aligned}
$$

\footnotetext{
*Corresponding author. Tel: +34 881016 017; Fax: +34 981167170

${ }^{\dagger}$ Associate Professor, Senior Member AIAA

\# Associate Professor
} 


$$
\begin{aligned}
& v \quad=\text { Poisson's ratio } \\
& \rho \quad=\text { Density } \\
& \sigma_{0} \quad=\quad \text { Initial stress } \\
& Q_{j}, b_{j}=\text { Material constants for the GFRP } \\
& f \quad=\quad \text { Yield surface or original objective function } \\
& g \quad=\quad \text { Flow potential } \\
& \sigma_{\mathrm{eq}} \quad=\quad \text { Von Mises stress } \\
& \sigma_{\mathrm{H}} \quad=\text { Hydrostatic stress } \\
& \alpha \quad=\quad \text { Shape factor of the yield ellipse } \\
& D \quad=\quad \text { Size of the vertical axis of the yield ellipse } \\
& \beta=\text { Shape of the flow potential ellipse on the meridional stress plane } \\
& v_{\mathrm{p}} \quad=\text { Plastic Poisson's ratio } \\
& p_{\mathrm{H}} \quad=\text { Hugoniot pressure } \\
& E_{\mathrm{H}} \quad=\text { Hugoniot specific energy } \\
& \Gamma \quad=\text { Grüneisen ratio } \\
& \rho_{0} \quad=\text { Reference density } \\
& \eta \quad=\quad \text { Nominal volumetric compressive strain } \\
& s \quad=\quad \text { Us-Up linear parameter } \\
& c_{0} \quad=\quad \text { Sound speed in the material } \\
& U_{\mathrm{s}} \quad=\quad \text { Shock wave speed } \\
& U_{\mathrm{p}} \quad=\quad \text { Particle speed } \\
& \mu \quad=\text { Dynamic viscosity }
\end{aligned}
$$

\section{Abbreviations}

FS $\quad=$ Fuselage station

HEA $\quad=$ Hybrid energy absorber

PET/W = Polyethylene Therephthalate $($ Welded $)$

TFLOPS $=$ Tera floating point operations per second

\section{Introduction}

Aircraft's edge over other forms of transport resides in its versatility, speed and safety. In the last decade, the fatality rate per billion passenger miles for aircraft travels was 750 times lower than road transport [1]. However, in the event of 
an airplane crash, severe injuries are more prone to occur than in any other transport. To address this issue, the military, commercial and general aviation industries adopted crashworthiness as a vital design criterion for the design process. This safety enhancement of aircrafts originates from Hugh DeHaven's generic principles for crashworthy structural designs: ensure the livable space, dissipate energy to protect the occupants and transmit forces to the strongest parts of the structures [2].

Different approaches have been sought over the past four or five decades to successfully apply these guidelines. Authors have considered several scenarios, including explosion blasts, foreign object impacts or hard landing crashes [3]. In order to improve the craft's responses in hard landing or water ditching situations, the main targets have typically been the sub-floor area [4], the main frames [5], and the vertical struts [6]. Ren et al. [7] proved that modified and enhanced subcargo regions with structures including honeycomb and foam reinforcements delivered remarkable energy absorption capabilities. When studying the primary frame structures, Schatrow and Waimer [8]'s improved crash concept example delivered a smoother energy absorption through parallel activation processes.

Vertical struts provide support for the floor structures and, in the event of an impact, they are subjected to mostly axial loads. The crashworthiness of an aircraft depends on the behavior of these structures: rigid struts help dissipate more energy on the lower sections of the aircraft, while flexible struts would maintain the integrity of the cabin's survivable cell after a crash [9, 10]. Research on the vertical struts has recently gained significance, with investigations looking into the effect of the material and design [11], location and orientation [6], the analysis of their crush behavior [12, 13], and the effect of the use of triggers [14]. The implementation of the vertical support struts not only provides support for the passenger floor, but it also alters the collapse process in an impact scenario [15]. A minor tilt of the struts in the aircraft's longitudinal axis can reduce the acceleration peak loads in a vertical impact [16] by altering the formation of the frames' plastic hinges. Ren and Xiang [14] also proved the benefits of trigger implementation, with peak accelerations being reduced by over $12 \%$.

In order to enhance the response of these tubular structures, inner reinforcements are usually added to complement tube's failure behavior [17]. The reinforcements are made from high density foam-like materials or brittle composites. The usage of these has gained importance in the aircraft industry, where they are now used as primary and secondary structures due to the high stiffness to weight ratios. When the struts are filled, the ductile collapse process of the outer tube is modified so as to obtain an stable crushing [18]. This, in turn, is achieved by obtaining a higher number of ordered folds, which yields a smoother response and higher energy absorption values [19].

This investigation is focused on the development and improvement of novel hybrid energy absorption devices intended for its usage in aeronautical applications. For that, a numerical model from a Boeing 737-200 fuselage section, previously developed through reverse engineering techniques and verified with both static internal pressure tests and a hard-landing impact, is used as a benchmark in which the effect of struts can be analyzed. This aircraft model, conceived in the mid 1960s, was not designed according to nowadays crashworthiness standards. Therefore, it becomes a suitable 
candidate to be fitted with hybrid energy absorbers acting as crushable vertical struts.

Two impact scenarios are considered, studying the collapse mechanisms and the crashworthiness performance of the structural configuration when colliding with solid ground and water. While full-scale hard-landing simulations are relatively common among the current literature [20, 21], water ditching assessment of aircraft and rotorcraft is far more scarce both on the experimental and numerical basis. Moreover, this impact environment is of crucial importance, as conventional subfloor structures tend to perform poorly in transmitting water pressure to the main structural features, which can lead to high acceleration of the airframe, distortion of the passenger floor, and even jamming or loss of doors [22]. The development of improved formulations for fluid-structure coupling, the Arbitrary Lagrangian-Eulerian method or the usage of particle discretization, has however allowed for faster and more realistic full-scale water ditching scenarios [23, 24]. For this investigation, the smoothed particle hydrodynamics method (SPH) developed by Gingold and Monaghan [25] is chosen to be coupled with the finite element software given its versatility, robustness and agreement with experimental data [26].

Once the numerical simulations with the original fuselage section are performed, the four hybrid vertical struts designed are fitted on the cargo area and the crash scenarios are again computed. The improvement induced by these structures is characterized according to aircraft efficiency and passenger biometric criteria.

\section{Numerical model and materials}

For the following study, a hard landing scenario from the Boeing 737-200 fuselage section in figure 1 is analyzed. The aircraft is dropped from a height of 4.27 meters, impacting the ground at $9.144 \mathrm{~m} / \mathrm{s}$, constituting a severe but survivable crash [27]. The validated numerical hard landing scenario from Paz et al. [15] is used as a starting point for assessing the crashworthiness improvement provided by hybrid energy absorbers used as vertical struts. Two scenarios were studied in that investigation, either including or excluding the auxiliary fuel tank in the cargo area. Since the latter case delivered the most harmful results as the fuel tank dissipates a significant amount of the vertical kinetic energy, it is chosen for this research. Further details on the validated numerical model are found in Paz et al. [15].

Seeking a significant crashworthiness improvement, an adapted version of the hybrid energy absorbers inspired by the designs from Costas et al. [29] was added to the fuselage section. These devices are composed of an outer aluminum tube filled with a star-shaped structure and foam extrusions filling the triangular cells in-between the composite plates, accounting for a total weight of $5.21 \mathrm{~kg}$. Concerning dimensions, the metallic tube is 200 millimeters long and has an edge of $55 \mathrm{~mm}$, while the inner core height is limited to $180 \mathrm{~mm}$ to reduce initial peak crushing forces [13]. The hybrid device is connected to the fuselage via vertical beams stiffer than the tube to ensure its collapse under vertical impact conditions. Furthermore, a two-millimeter trigger is implemented on the upper tube end to reduce high initial peak forces and ease a stable collapse of the structure [29]. Figure 2] shows the trigger locations and displacement direction implemented on the tube. The absorbers are rotated 45 degrees along the vertical axis to reduce global buckling along 


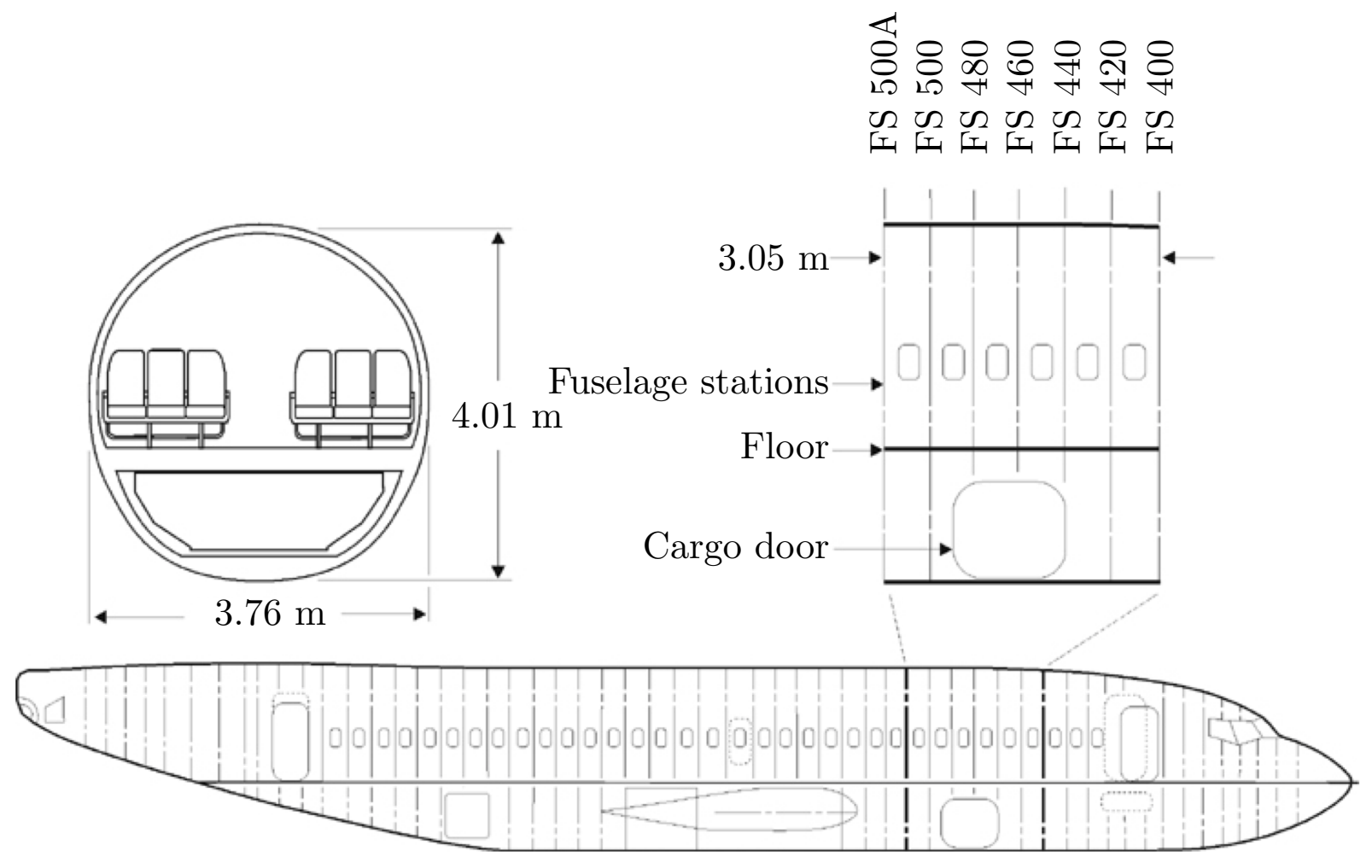

Fig. 1 Boeing 737-200 test section. Taken from [28]. 
the longitudinal direction. Absorbers, they are placed at every other frame while leaving a transversal clearance of 2.04 $\mathrm{m}$ to ensure necessary capacity for standardized cargo containers [30]. Two rigid plates are added to the top and bottom ends of the tube to distribute the vertical load along the edges, resulting in the structural design shown in figure 3 .

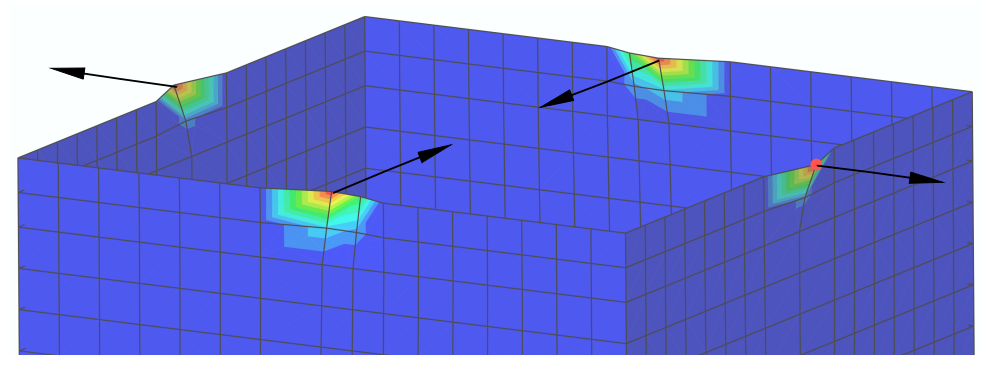

Fig. 2 Two-millimeter trigger on lower edges of HEA.

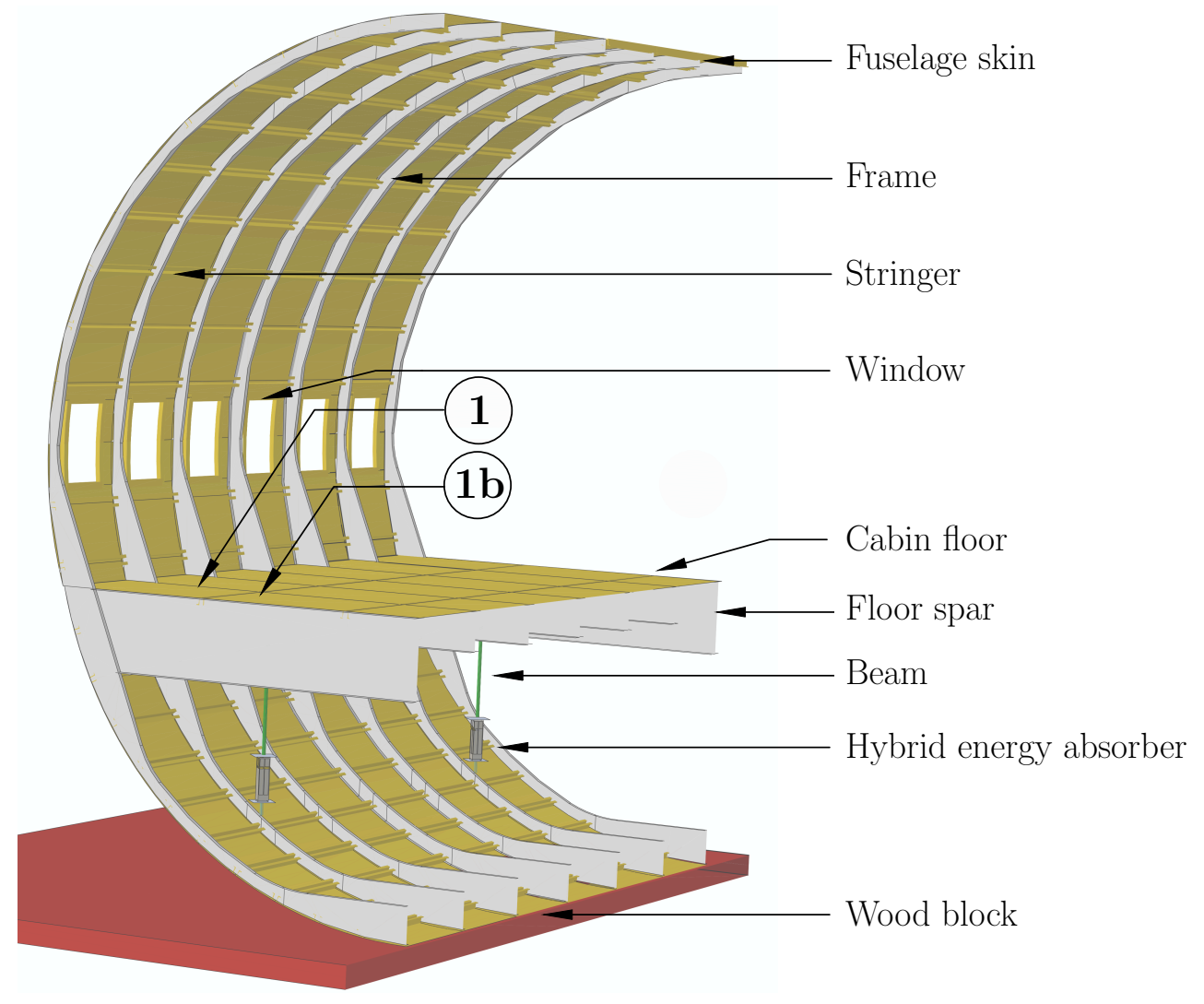

Fig. 3 Structural detail of enhanced aircraft fuselage.

The tube's inner core is made from an intertwined four-plate star-shaped skeleton and triangular foam extrusions filling the gap between tube and reinforcement. A one millimeter gap is left between the core and tube to avoid computational instabilities, while easing a hypothetical manufacturing process. A three dimensional cut of the proposed hybrid absorber is presented in figure 4 


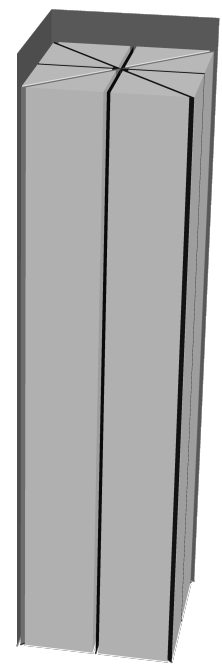

Fig. 4 Three-dimensional cut of the hybrid energy absorber.

To accurately capture the deformation process of all components, detailed material models have been chosen for the research. The outer tube from the absorbers is made from the AA2024-T3 aluminum alloy used in the fuselage, modeled with the Johnson-Cook strain-rate sensitive plasticity models [31] without temperature effects. The glass-fiber-reinforced polyamide (GFRP) Ultramid A3WG10 BK00564 from BASF is used for the inner plates. The material model, calibrated from the tensile tests [29], is implemented as an isotropic material considering the visco-elastic behavior in the plastic region. The behavior of polymeric foam from Armacell (ArmaFORM PET/W AC 135) used to fills the voids between the GFRP skeleton was also modeled after numerous material tests [29], later implemented following the isotropic foam hardening model proposed by Deshpande and Fleck [32] for metallic foams. A pressure-dependent yield surface $f$ and a flow potential function $g$ to represent non-associated flow are also considered. The parameters for each of the material models are detailed in tables 1 and 2 , while a more in-depth description of the constitutive equations can be found in Paz et al. [15].

\begin{tabular}{rcrrrrrc}
\hline $\mathrm{E}(\mathrm{GPa})$ & $v$ & $\rho\left(\mathrm{kN} / \mathrm{m}^{3}\right)$ & $\sigma_{0}(\mathrm{MPa})$ & $Q_{1}(\mathrm{MPa})$ & $Q_{2}(\mathrm{MPa})$ & $b_{1}$ & $b_{2}$ \\
\hline 15.48 & 0.40 & 15.15 & 25.00 & 124.86 & 44.46 & 315.89 & 5748.46 \\
\hline \multicolumn{7}{c}{ Table 1 } & Material properties of Ultramid A3WG10 BK00564.
\end{tabular}

Table 1 Material properties of Ultramid A3WG10 BK00564.

\begin{tabular}{rcrccc}
\hline$E(\mathrm{MPa})$ & $v$ & $\rho\left(\mathrm{kN} / \mathrm{m}^{3}\right)$ & $\alpha$ & $\beta$ & $v_{\mathrm{p}}$ \\
\hline 59.01 & 0.10 & 1.35 & 0.729 & 1.76 & 0.111
\end{tabular}

Table 2 Material properties of ArmaFORM PET/W AC 135. 


\begin{tabular}{ccc}
\hline$E$ & $v$ & $\rho$ \\
\hline $500.00 \mathrm{MPa}$ & 0.30 & $12.00 \mathrm{kN} / \mathrm{m}^{3}$ \\
\hline
\end{tabular}

Table 3 Material properties of the wood for the impacting surface.

Two impacting surfaces are considered in this research, the wooden platform from the original hard-landing experiment and a 1.5 meter-deep square water pool with an edge of six meters to represent a water-ditching scenario. While wood is implemented as a elastic material with the properties from table 3, the water pool is simulated using particle methods, thus requiring the definition of an equation of state (EOS). The Mie-Grüneisen EOS [33, 34] implemented, linear in energy, follows the form

$$
p-p_{\mathrm{H}}=\Gamma \rho\left(E_{\mathrm{m}}-E_{\mathrm{H}}\right)
$$

where $p_{\mathrm{H}}$ and $E_{\mathrm{H}}$ are the density-dependent Hugoniot pressure and specific energy, and $\Gamma$ is the Grüneisen ratio defined by

$$
\Gamma=\Gamma_{0} \frac{\rho_{0}}{\rho}
$$

with $\Gamma_{0}$ being a material constant and $\rho_{0}$ the reference density. Moreover, the Hugoniot energy can be expressed as

$$
E_{\mathrm{H}}=\frac{p_{\mathrm{H}} \eta}{2 \rho_{0}}
$$

where $\eta$ is the nominal volumetric compressive strain, defined as $\eta=1-\rho_{0} / \rho$. In the linear $U_{\mathrm{s}}-U_{\mathrm{p}}$ Hugoniot form, the Hugoniot pressure is defined by

$$
p_{\mathrm{H}}=\frac{\rho_{0} c_{0}^{2} \eta}{(1-s \eta)^{2}},
$$

where $s$ and the sound speed of the material $c_{0}$ define the linear relationship between the shock velocity $U_{\mathrm{s}}$ and the particle velocity $U_{\mathrm{p}}$ as

$$
U_{\mathrm{s}}=c_{0}+s U_{\mathrm{p}}
$$

Finally, coupling equations (1), (2), (4) and (5) leads to the Hugoniot general expression

$$
p=\frac{\rho_{0} c_{0}^{2} \eta}{(1-s \eta)^{2}}\left(1-\frac{\Gamma_{0} \eta}{2}\right)+\Gamma_{0} \rho_{0} E_{\mathrm{m}},
$$


with a limiting compression value given by

$$
\rho_{\lim }=\frac{s \rho_{0}}{s-1}
$$

The shock Hugoniot parameters for water were extracted from Courchinoux and Lalle [35] considering that particle speeds do not surpass $700 \mathrm{~m} / \mathrm{s}$, and have been detailed table 4 . The dynamic viscosity of water at 25 degrees Celsius, $\mu=0.89 \mathrm{mPa} \cdot \mathrm{s}$, was also included in the material constitutive model considering its effect on the collision between the fuselage skin and the water surface.

\begin{tabular}{rrrcc}
\hline$\rho\left(\mathrm{kN} / \mathrm{m}^{3}\right)$ & $\mu(\mathrm{mPa} \cdot \mathrm{s})$ & $c_{0}(\mathrm{~m} / \mathrm{s})$ & $s$ & $\Gamma_{0}$ \\
\hline 10.00 & 0.89 & 1483.00 & 1.75 & 0.4934 \\
\hline
\end{tabular}

Table 4 General and shock Hugoniot parameters for water. Extracted from Courchinoux and Lalle [35].

\section{Mesh and analysis settings}

The characteristics of these numerical simulations required the usage of different element natures and sizes as to obtain efficient yet accurate results. In the case of the fuselage structures, four-node shell elements with reduced integration (S4R) were chosen to mesh the outer skin, passenger floor, main frames and floor beams. The usage of these elements for the frames and beams helps capture more accurately the local buckling and crippling undergone during the crash. In the case of the longitudinal stiffeners, the modeling is simplified to 2-node linear beam elements (B31) as to reduce the number of degrees of freedom of the simulation. The mesh size used for the fuselage structural features ranges between $20 \mathrm{~mm}$ and $75 \mathrm{~mm}$ depending on the component, as detailed in table 5

\begin{tabular}{llrr}
\hline Item & Element type & Element no. & Avg. size (mm) \\
\hline Fuselage & S4R & 9959 & 75 \\
Fuel tank & S4R & 3150 & 50 \\
Frames & S4R & 30219 & 20 \\
Stringers & B31 & 2863 & 75 \\
Wood platform & C3D8R & 19200 & 50 \\
Water pool & PC3D & 61425 & 80 \\
Occupants and seats & Point masses & 20 & - \\
\hline HEA tube & S4R & 19584 & 7 \\
HEA plates & S4R & 18880 & 3 \\
HEA foam & C3D8R & 101008 & 3 \\
\hline
\end{tabular}

Table 5 Type, number and size of the finite elements used. 
In the case of the hybrid energy absorbers, mesh sizes need to be reduced by an order of magnitude to accurately capture the collapse process of the component. Whereas shells are used for the tube and GFRP, 8-node solid elements with reduced integration $(\mathrm{C} 3 \mathrm{D} 8 \mathrm{R})$ are required for modeling the foam. Finally, the two impacting surfaces considered are also meshed. The wood platform is composed of solid elements, while the water pool is made from over 61000 three-dimensional particles (PC3D) by the smoothed particle hydrodynamics method with a cubic Kernel function. The mesh sizes and number of elements for the absorbers and impacting surfaces has been tabulated in table 5

The finite element modeling, meshing, and simulation were performed using the Abaqus 6.16 software and its Explicit package. The first and second steps entailed the usage of the user interface, while the 100 ms simulations were parallelized into 16 domains and run in a high performance computing cluster with a theoretical peak performance of 7.6 TFLOP'S. Artificial-to-internal energy balances were checked for all simulations, resulting in values under 7\% as recommended by the literature for this type of crashworthiness analysis [36]. Computational costs varied, as all four models required distinct simulation times due to their singularities. The results from the hard-landing scenario without energy absorbers were obtained after $17 \mathrm{~h}$ with an average stable time increment of $1.3 \mu$ s. In the case of the enhanced fuselage, the stable increment dropped to $0.35 \mu$ s considering the smaller mesh sizes from the absorbers. Subcycling techniques were used to reduce computational time and obtain results in $23 \mathrm{~h}$. The water ditching scenarios were hindered by the more costly SPH technique, especially considering that no subcycling could be used with particle methods. Simulations run for $31 \mathrm{~h}$ with the original fuselage and $102 \mathrm{~h}$ for the enhanced section.

The results from the fuselage section are analyzed according to biometric criteria with the data extracted from the two representative locations $\mathbf{1}$ and $\mathbf{1 b}$ in figure 3 at the floor level. The data from location $\mathbf{1}$ is extracted given the inheritance of the previous validation against the experimental test data from Fasanella and Jackson [27]. However, location $\mathbf{1 b}$ is selected as it vertically coincides with the insertion of the front left hybrid absorber as to assess any possible harmful effects. Acceleration histories were treated with a 48-Hz four-pole Butterworth low-pass filter forwards and backwards. Moreover, the Eiband diagram for vertical accelerations [37] is also used to assess passenger injury, classifying accelerations according to their peak and duration and dividing predicted human responses into the voluntary exposure, moderate injury and severe injury regions.

\section{Results}

Results from the four numerical simulations are presented, first studying the benefits arising from the usage of hybrid energy absorbers as vertical struts discerning between hard-landing and water-ditching scenarios. Moreover, the response of the fuselage for both impacted mediums is also compared. 


\section{A. Hard-landing}

The first of the fuselage impact scenarios considered studies the hard-landing of the aircraft section replicating the conditions from the experimental test. Results show harmful responses at both measured locations, with acceleration peak values of $47.5 \mathrm{~g}$ and $81.6 \mathrm{~g}$ at locations 1 and $1 \mathrm{~b}$ respectively, as seen in table 6 However, as the four hybrid energy absorbers are added to the fuselage section, acceleration peaks were reduced from $47.6 \mathrm{~g}$ to $36.8 \mathrm{~g}$ at location $\mathbf{1}$ and from $81.6 \mathrm{~g}$ to $61.3 \mathrm{~g}$ at location $\mathbf{1 b}$, constituting over a $23 \%$ peak decrease.

\begin{tabular}{lrrrr}
\hline & \multicolumn{2}{c}{ Original fuselage } & \multicolumn{2}{c}{ Enhanced fuselage } \\
\cline { 2 - 5 } Location & Max $(\mathrm{g})$ & Avg $(\mathrm{g})$ & Max $(\mathrm{g})$ & Avg $(\mathrm{g})$ \\
\hline 1 & 47.62 & 12.11 & 36.83 & 12.37 \\
$\mathrm{~b}$ & 81.69 & 22.10 & 61.31 & 19.58 \\
\hline
\end{tabular}

Table 6 Acceleration maximums and averages for the fuselage hard-landing scenario. Comparison between original and enhanced fuselage sections.

A closer examination at the data obtained from both analyses was performed by studying the acceleration trends as presented in figure 5a. The response from the enhanced fuselage shows higher acceleration peaks during the first 20 ms of the simulation given the increased structural stiffness of the fuselage with the hybrid absorbers. Moreover, the acceleration-history plots are also studied in the Eiband diagram from figure $5 \mathrm{~b}$, showing that the acceleration trend at location $\mathbf{1 b}$ from the original fuselage is well into the severe injury region, whereas that is nearly avoided for the enhanced section. The injury rating at location $\mathbf{1}$ is also reduced on account of lower peak accelerations.

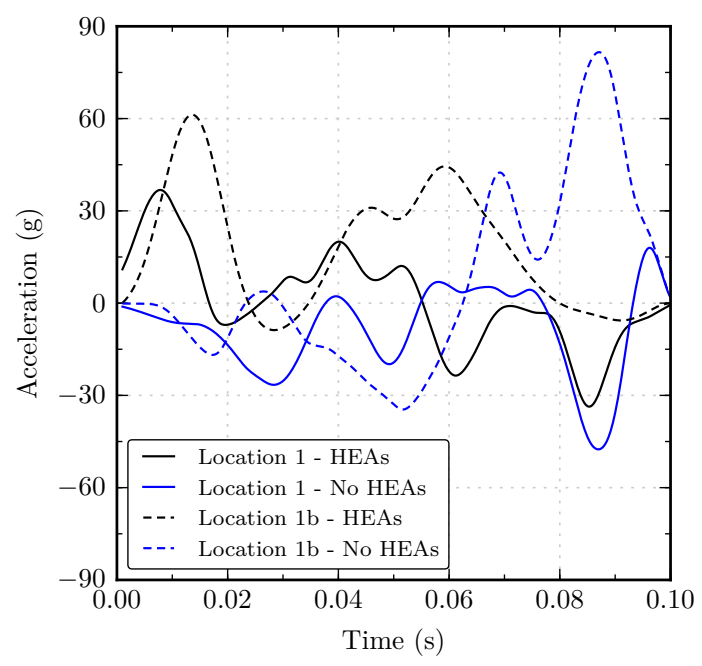

(a) Aircraft acceleration response.

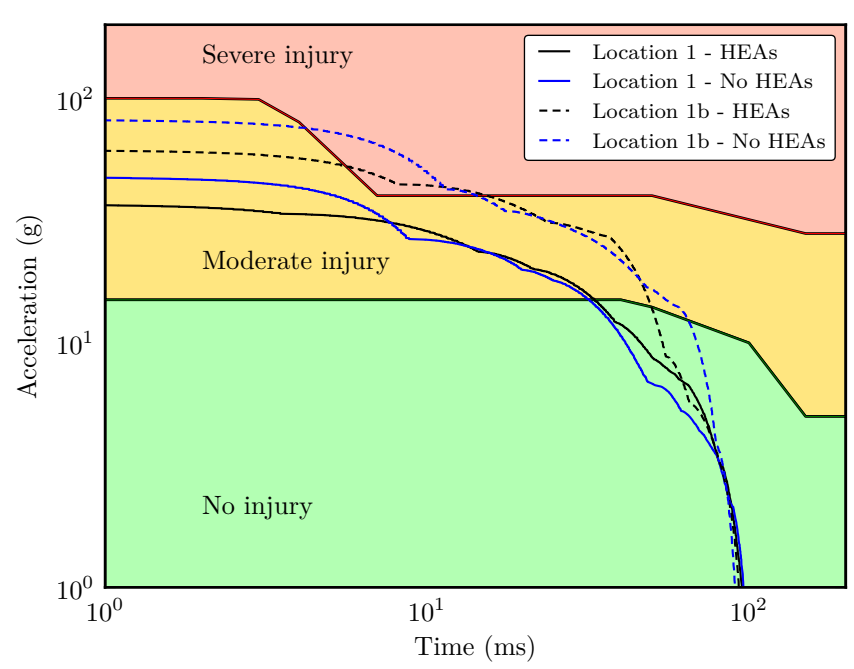

(b) Vertical accelerations depicted in Eiband diagram.

Fig. 5 Aircraft responses in hard-landing scenario, with and without hybrid energy absorbers, for locations $\mathbf{1}$ and $\mathbf{1 b .}$

The usage of absorbers also limits the deformation of the subfloor structures in the later stages of the collapse 
process, avoiding the impact of the main frames with the passenger floor beams and consequently reducing acceleration values. In the post test images from figure 6, different collapse processes are seen for both models. The fuselage from figure 6a reveals high deformation values at the cargo region, as the frames only dissipate a limited amount of energy localized at local plastic hinges. Consequently, the aircraft's crash stroke is rapidly exhausted, leading to impact of the lower part of the frames with the passenger floor. This effect not only increases acceleration peaks at the occupant locations, but can also lead to higher injury risk by environmental factors. In the enhanced fuselage from figure 6b, a higher survivable volume is maintained in the cargo area.

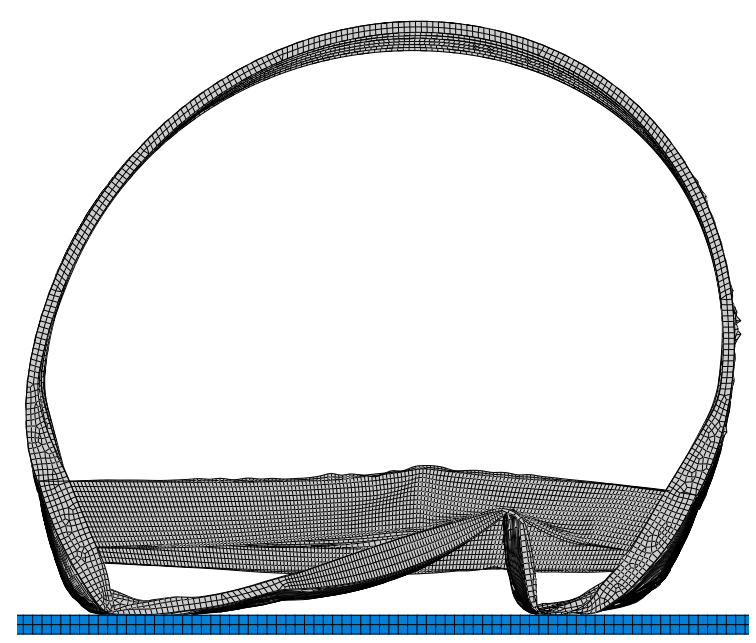

(a) Fuselage without energy absorbers.

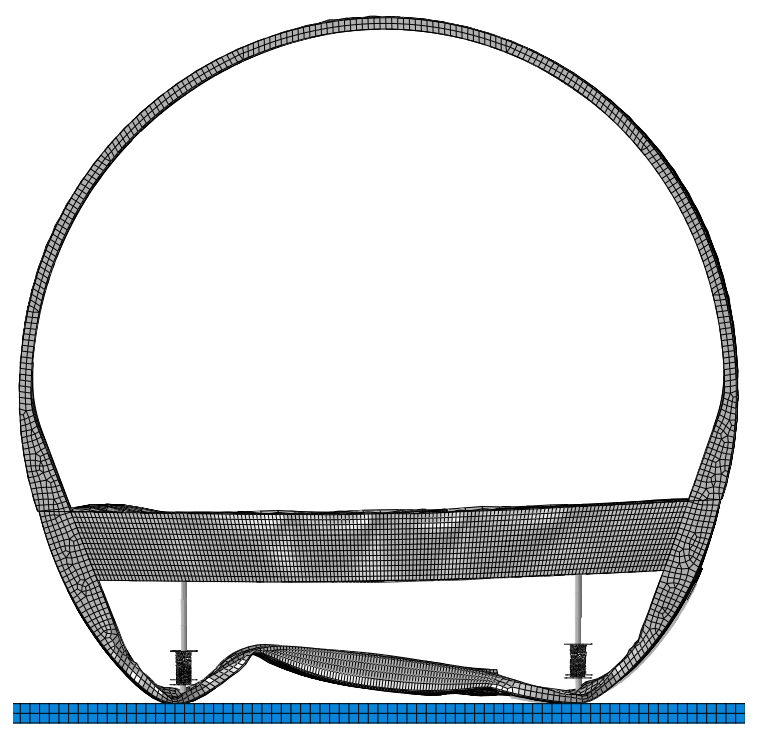

(b) Fuselage with hybrid energy absorbers.

Fig. 6 Deformation of the specimen after hard-landing scenario, without and with hybrid energy absorbers.

Furthermore, this constrained frame collapse also leads to a higher exploitation of the plastic dissipation capabilities of the structures, as shown in the energy graph from figure 7 The energy absorbed by the frames through plasticity is increased from the original $75 \mathrm{~kJ}$ to $81 \mathrm{~kJ}$, yielding an overall energy dissipation increase of over $10 \mathrm{~kJ}(11 \%)$ of the global fuselage structures. Hybrid absorbers also contribute by further dissipating $8.8 \mathrm{~kJ}$ though progressive collapse.

Moreover, figures $8 \mathrm{a}$ and $8 \mathrm{~b}$ elucidate the behavior offered by the energy absorber proposed under location $\mathbf{1 b}$. The crash response in figure $8 \mathrm{~b}$, filtered with a SAE 600 filter, shows a low initial peak of $66 \mathrm{kN}$ for the initiation of the strut's collapse, followed by a crushing force in the range of $30-45 \mathrm{kN}$ throughout most of the crushing. However, as the after $90 \mathrm{~ms}$ the vertical strut ceases to absorb and dissipate energy as the fuselage's cargo compartment stops collapsing.

\section{B. Water-ditching}

A similar approach to the hard-landing simulation and analysis was followed for the water ditching scenario. A visual comparison between the both aircraft sections in figure 9 hints the crashworthiness improvement obtained from the 


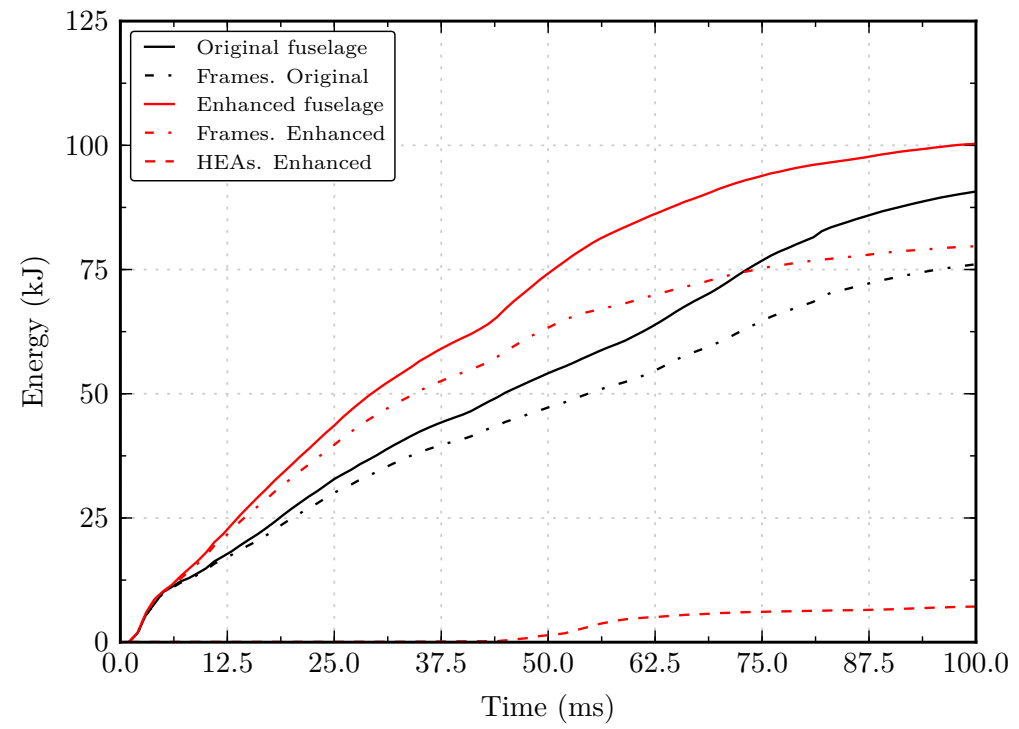

Fig. 7 Plastic energy dissipation during hard landing scenario. Comparison between original and enhanced fuselage with energy absorbers.

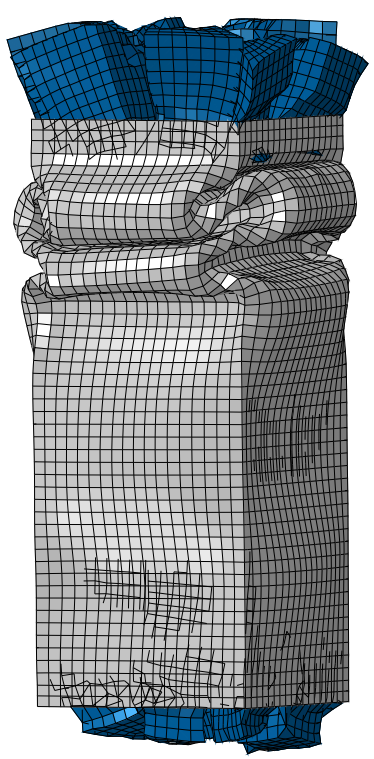

(a) Final deformation of strut under location $\mathbf{1 b}$.

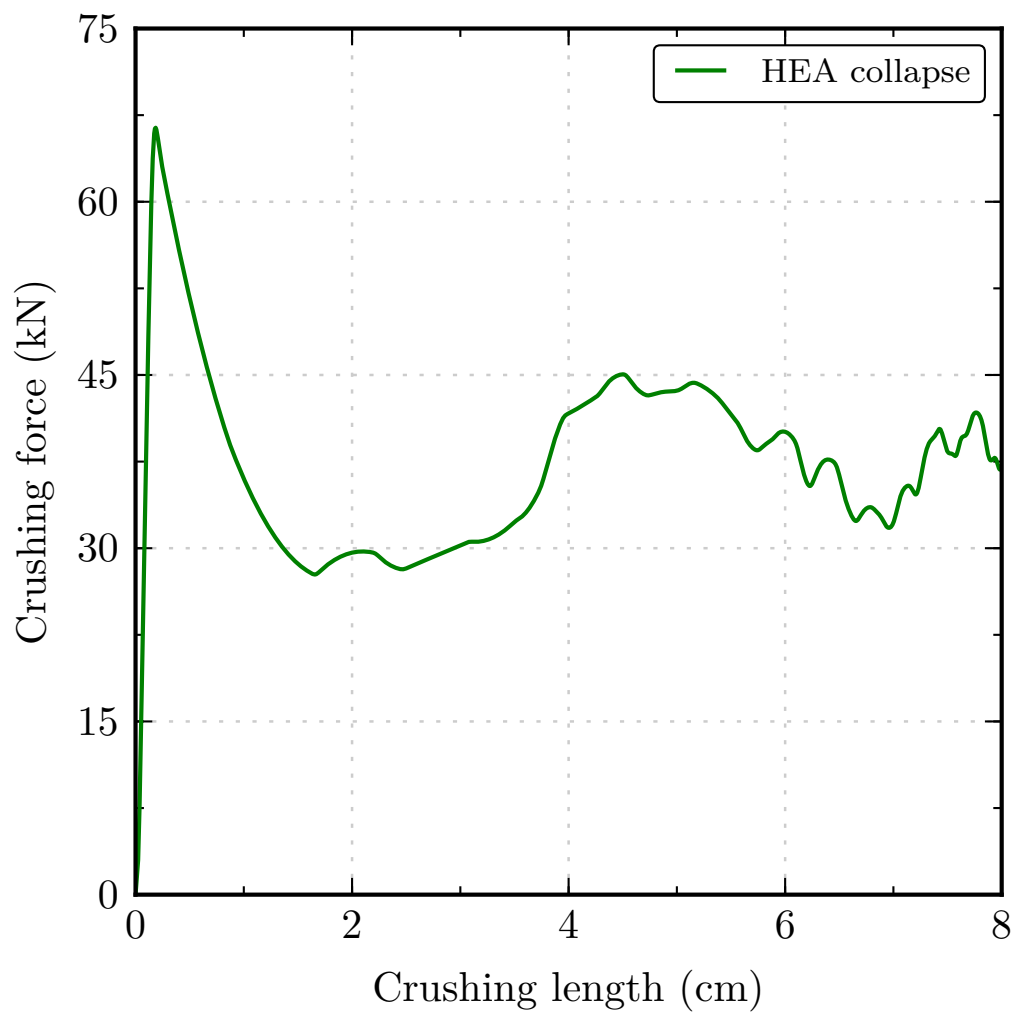

(b) Response of strut under location $\mathbf{1 b}$.

Fig. 8 Vertical strut after impact and response. 
usage of crushable vertical struts. Although the subcargo area appears to yield a similar collapse, the overall structural integrity of the craft if better maintained when using the absorbers, avoiding failure and bending of the floor spars, with the upper part of the frames retaining a closer shape to the original configuration.

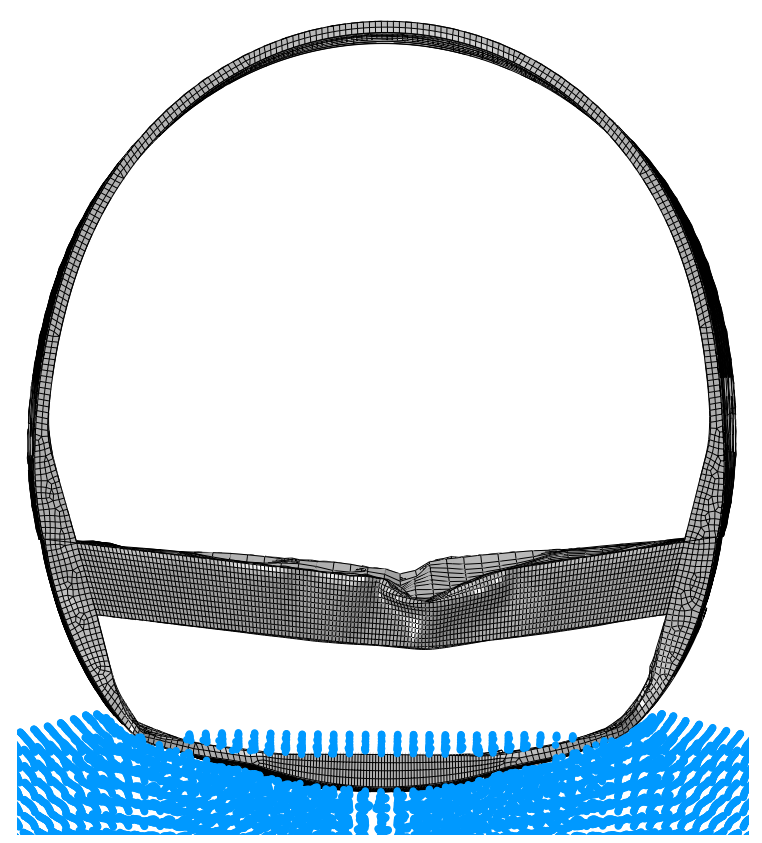

(a) Fuselage without energy absorbers.

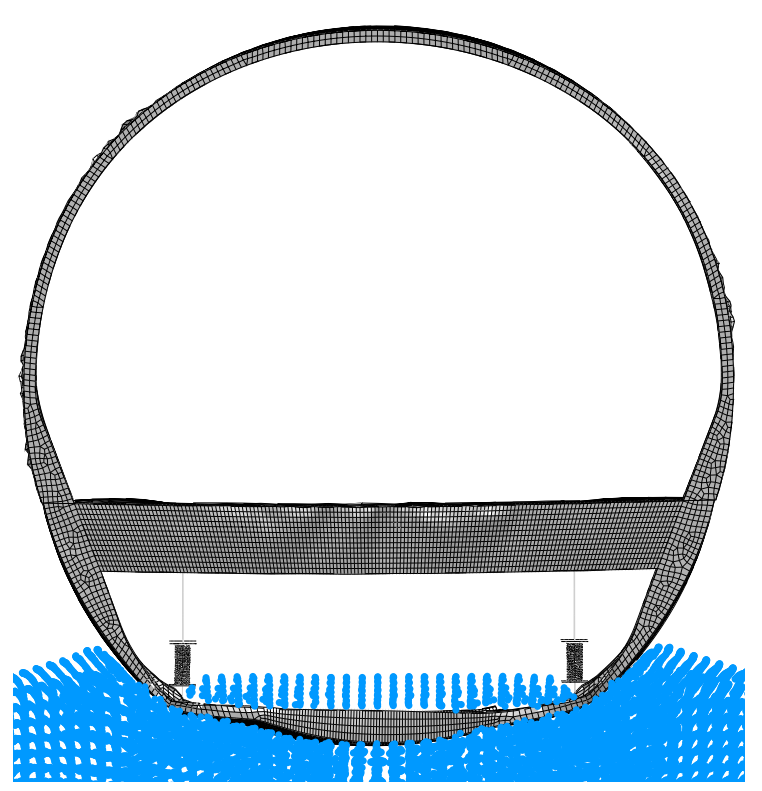

(b) Fuselage with hybrid energy absorbers.

Fig. 9 Deformation of the specimen after water ditching scenario, without and with hybrid energy absorbers.

When studying the acceleration histories for both numerical simulations in figure $10 \mathrm{a}$, slightly higher acceleration peaks are obtained for the fuselage featuring energy absorbers, although average values are maintained for location $\mathbf{1 b}$ and reduced at location $\mathbf{1}$. This difference, tabulated in table 7 , arises from the increased stiffness provided by the vertical struts, which yields the acceleration maximums during the first stages of the impact. In the case of the original fuselage, acceleration values exceed those from the enhanced section for the last $60 \mathrm{~ms}$ of the simulation, as the latter model offers a more progressive crushing of the components. Consequently, after the transformation of the accelerations into the diagram from figure $10 \mathrm{~b}$ injury ratings are moderately increased for the enhanced section for short acceleration pulses, although graphs are still kept in the moderate injury region for both locations.

\begin{tabular}{lrrrr}
\hline & \multicolumn{2}{c}{ Original fuselage } & \multicolumn{2}{c}{ Enhanced fuselage } \\
\cline { 2 - 5 } Location & Max $(\mathrm{g})$ & Avg $(\mathrm{g})$ & Max $(\mathrm{g})$ & Avg $(\mathrm{g})$ \\
\hline 1 & 28.62 & 10.24 & 39.67 & 8.46 \\
$\mathrm{~b}$ & 25.34 & 10.15 & 35.27 & 10.31 \\
\hline
\end{tabular}

Table 7 Acceleration maximums and averages for the fuselage water ditching scenario. Comparison between original and enhanced fuselage sections. 


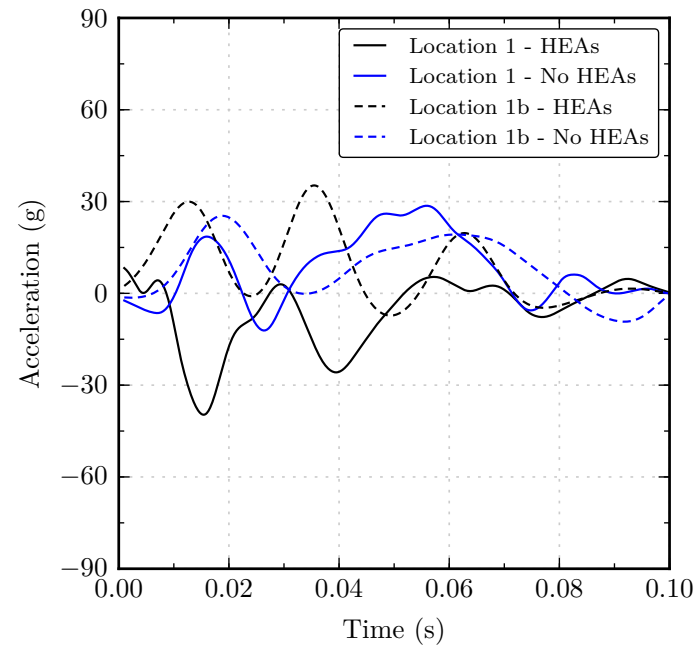

(a) Aircraft acceleration response.

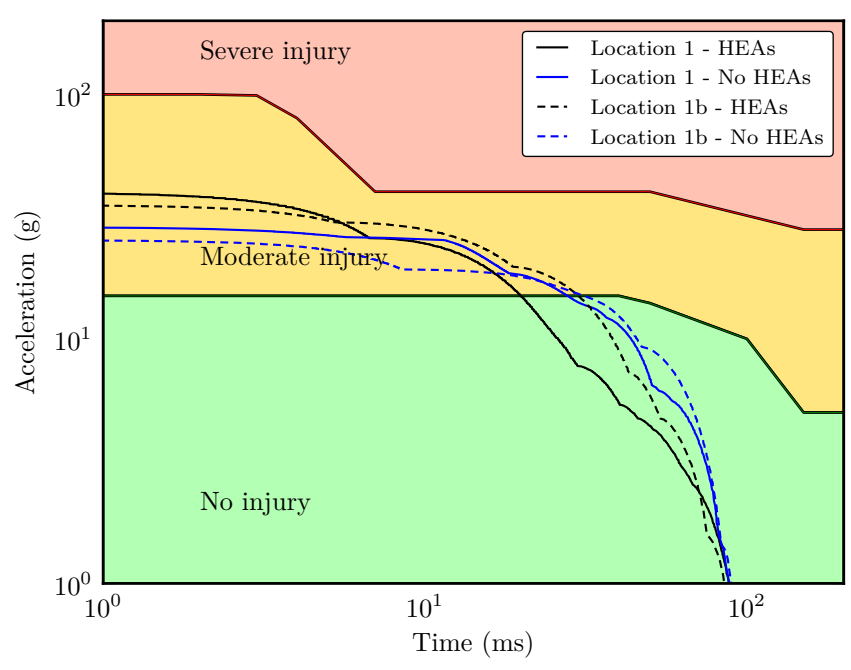

(b) Vertical accelerations depicted in Eiband diagram.

Fig. 10 Aircraft responses in water-ditching scenario, with and without hybrid energy absorbers, for locations 1 and 1b.

The energy absorption evolution of the fuselage structures is also studied, showing an even greater difference between models than in the hard landing scenario. While frames originally dissipated $37.4 \mathrm{~kJ}$ of the initial kinetic energy, the smoother and broader hinge formation leads to an increase of $35 \mathrm{~kJ}$, resulting in a total absorption of $72.7 \mathrm{~kJ}$ for the enhanced section. This, added to the $4 \mathrm{~kJ}$ absorbed by the vertical struts, boosts the global plastic dissipation from $45.2 \mathrm{~kJ}$ to $86.3 \mathrm{~kJ}$, almost doubling the initial capabilities of the fuselage structures.

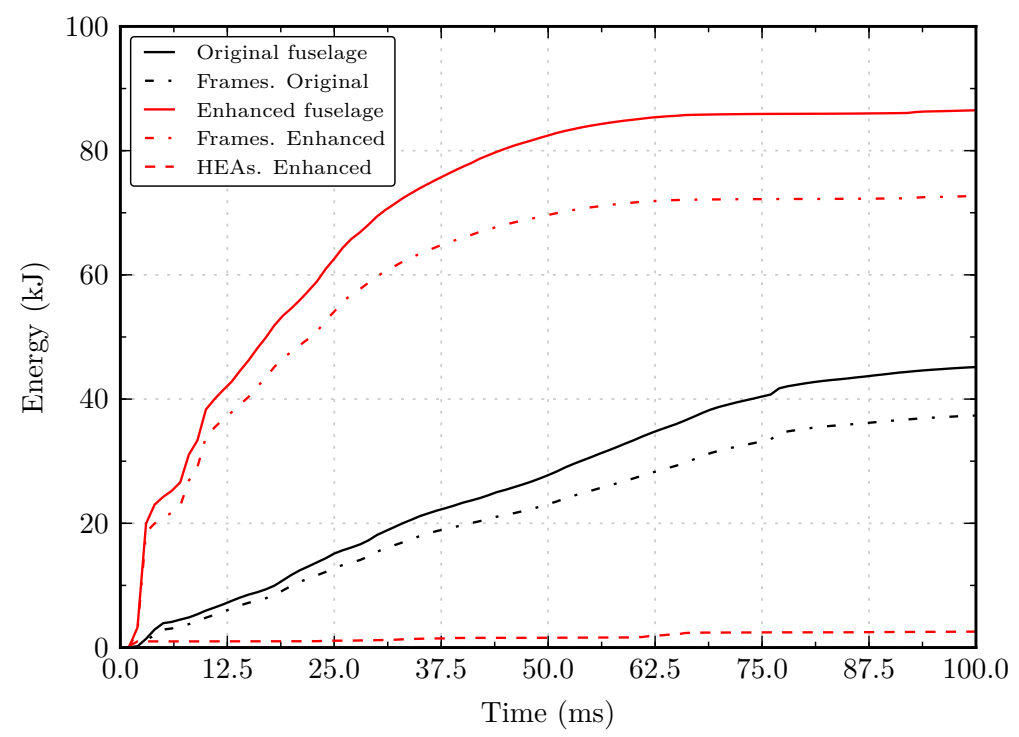

Fig. 11 Plastic energy dissipation during water ditching scenario. Comparison between original and enhanced fuselage with energy absorbers. 


\section{Hard-landing versus water-ditching}

As a last approach, the performance of the fuselage is analyzed and compared between both impacting surfaces. First, the biometric responses of the unmodified sections are contrasted in figures $12 \mathrm{a}$ and $12 \mathrm{~b}$, revealing significantly higher accelerations for the impact against solid grounds. In the case of the ditching, the distribution of the impact loads along the skin surface by means of the membrane effect leads to lower acceleration peaks and a reduced injury rating in the Eiband diagram.

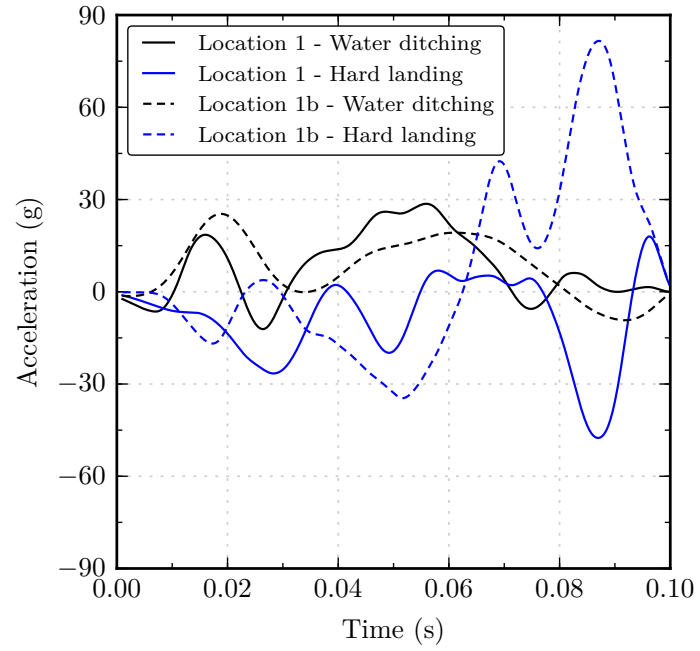

(a) Aircraft acceleration response.

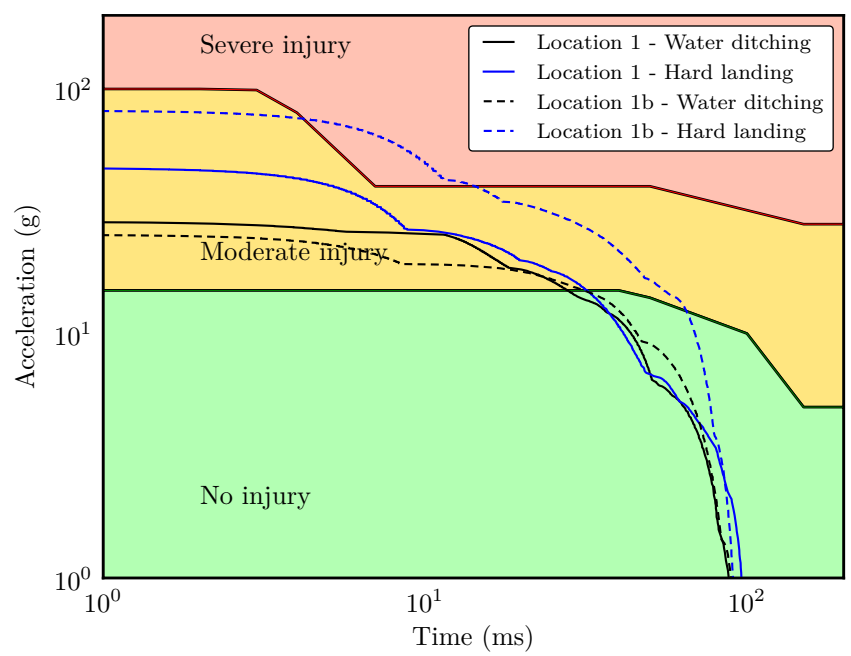

(b) Vertical accelerations depicted in Eiband diagram.

Fig. 12 Aircraft responses in hard-land and water-ditching scenarios without hybrid energy absorbers for locations 1 and $\mathbf{1 b}$.

This particular discrepancy when varying the impacting mediums is also observed for the enhanced sections, as shown in figures $13 \mathrm{a}$ and $13 \mathrm{~b}$. However, the usage of hybrid absorbers limits this difference between both scenarios, yielding more severe acceleration maximums at location $\mathbf{1 b}$ while similar injury predictions are obtained for location $\mathbf{1}$.

Additionally, energy dissipation trends from figure 14 also reveal different structural behaviors between both impact conditions. Plastic dissipation in water ditching is governed by more steep curve during the first $60 \mathrm{~ms}$ of the analysis, where it nearly reaches its final value of $86.3 \mathrm{~kJ}$. During the impact on the wood block, however, plastic dissipation is more progressive, constantly increasing up to surpassing the $100 \mathrm{~kJ}$ threshold. This distinct comportment stems from the manner in which the impact loads are transmitted to the fuselage structures, as the water pool allows for a more evenly distributed loading along the lower structural components of the aircraft.

\section{Conclusions}

For this research, thin-walled hybrid energy absorbers are developed to work as vertical struts under axial impact loads on fuselage aircraft structures. Rather than studying their response as standalone components, these devices are 


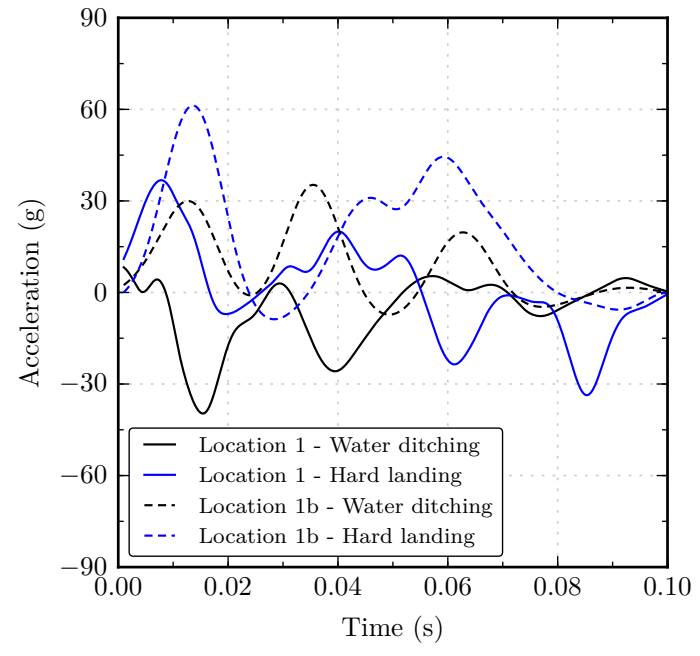

(a) Aircraft acceleration response.

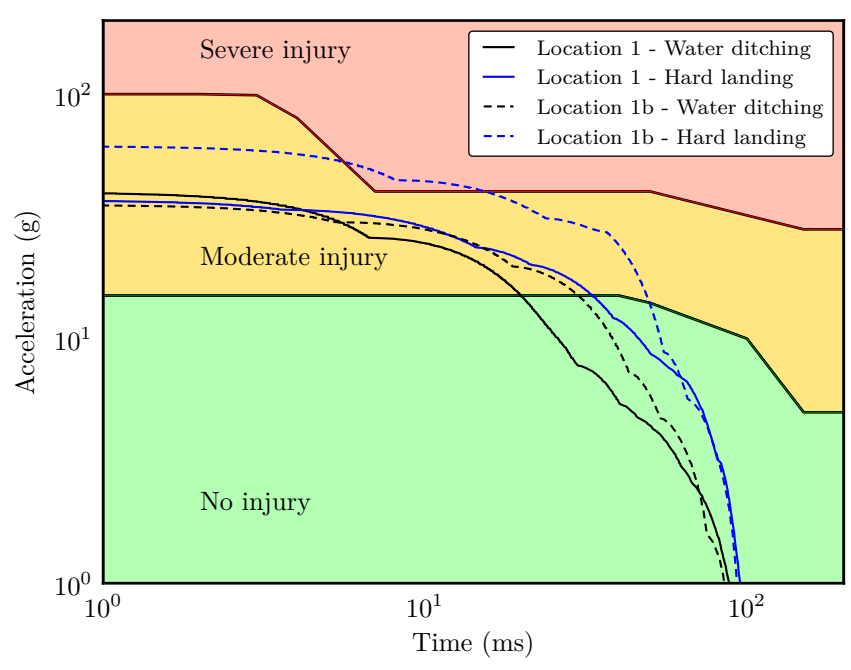

(b) Vertical accelerations depicted in Eiband diagram.

Fig. 13 Aircraft responses in hard-land and water-ditching scenarios with hybrid energy absorbers for locations $\mathbf{1}$ and $1 b$.

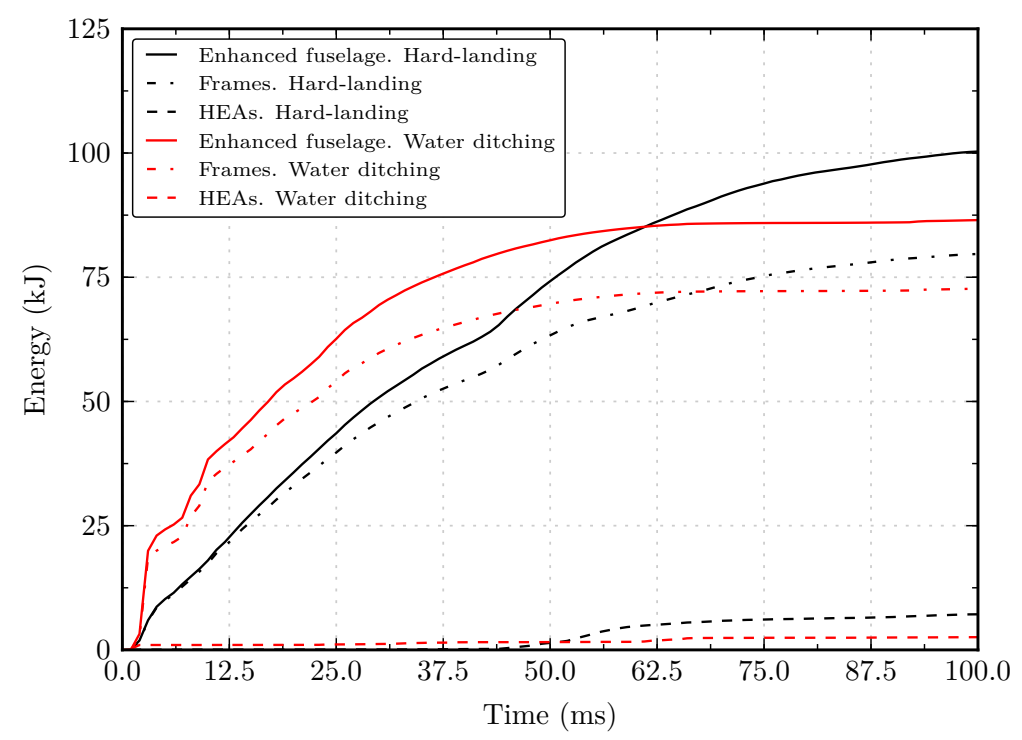

Fig. 14 Plastic energy dissipation during hard landing and water ditching scenarios for enhanced fuselage sections with hybrid energy absorbers. 
added to a 3.048-meter long fuselage section from a previously validated Boeing 737-200 without the auxiliary fuel tank. The simulation is studied for two impacting surfaces, considering hard-landing and water-ditching scenarios. Crashworthiness metrics are evaluated before and after the implementation of the energy absorbers to determine their overall effect on the aircraft, as well as comparing the collapse evolution of the fuselage after colliding with both impacted surfaces. The following conclusions are drawn:

- In a hard-landing scenario, the usage of hybrid energy absorbers as vertical struts in aircraft structures modifies the collapse evolution of the fuselage, yielding acceleration peaks reduced by over $23 \%$ at the two data extraction locations. The injury prediction is also lowered according to the Eiband diagram for vertical accelerations.

- Aircraft water ditching accelerations are slightly worsened from the usage of hybrid vertical struts, with a peak increase of $10 \mathrm{~g}$ at the measured locations, while maintaining similar values of average acceleration.

- The study of energy dissipation trends reveals a higher exploitation of the global structural plastic dissipation capabilities for both scenarios, with hybrid absorbers leading to an increase of over $10 \mathrm{~kJ}$ and $40 \mathrm{~kJ}$ for the hard-landing and water ditching respectively.

- An energy comparison between both impact scenarios for the enhanced sections also shows a higher and more gradual energy dissipation for ground impact conditions. The water pool distributes crash forces more abruptly along the lower fuselage structures due to the membrane effect between the fuselage skin and the water surface, resulting in a more steep energy absorption curve that ceases $60 \mathrm{~ms}$ after the impact.

- The usage of hybrid energy absorbers as vertical struts improves the crashworthiness of aircraft structures under vertical impact scenarios, yielding higher protection for passengers by reducing accelerations and increasing the survivable volume, as well as modifying and enhancing the airframe structural collapse mechanism.

\section{Acknowledgements}

The research leading to these results has received funding from the Spanish Goverment (Ministerio de Economía y Competitividad) under grant agreement DPI2016-76934-R, as well as funding from the Fundación Barrié. The authors fully acknowledge the support received.

\section{References}

[1] Research and Innovative Technology Administration, Bureau of Transportation Statistics, "Transportation Statistics Annual Report 2010,” Tech. rep., U.S. Department of Transportation, Washington DC, 2011.

[2] De Haven, H., Accident survival-airplane and passenger automobile, Crash Injury Research Project, 1952.

[3] Heimbs, S., "Energy absorption in aircraft structures," International Workshop on Hydraulic Equipment and Support Systems for Mining, 2012. 
[4] Wiggenraad, J. F. M., Michielsen, A., Santoro, D., Le Page, F., Kindervater, C., Beltran, F., and Alkhalil, M., "Finite element methodologies development to simulate the behaviour of composite fuselage structure and correlation with drop test," Air and Space Eur 33, 2001, pp. 228-233. doi:10.1016/s1290-0958(01)90102-9.

[5] Woodson, M. B., Johnson, E. R., and Haftka, R. T., "Optimal design of composite fuselage frames for crashworthiness," International Journal of Crashworthiness, Vol. 1, No. 4, 1996, pp. 369-380. doi:10.1533/cras.1996.0027.

[6] Ren, Y., and Xiang, J., "A comparative study of the crashworthiness of civil aircraft with different strut configurations," International Journal of Crashworthiness, Vol. 15, No. 3, 2010, pp. 321-330. doi:10.1080/13588260903343823.

[7] Ren, Y., Xiang, J., Zheng, J., and Luo, Z., "Crashworthiness analysis of aircraft fuselage with sine-wave beam structure," Chinese Journal of Aeronautics, Vol. 29, No. 2, 2016, pp. 403-410. doi:10.1016/j.cja.2016.02.002.

[8] Schatrow, P., and Waimer, M., "Crash concept for composite transport aircraft using mainly tensile and compressive absorption mechanisms," CEAS Aeronautical Journal, Vol. 7, No. 3, 2016, pp. 471-482. doi:10.1007/s13272-016-0203-6.

[9] Kumakura, I., Minegishi, M., and Iwasaki, K., "Impact simulation of simplified structural models of aircraft fuselage,” 2000 World Aviation Conference, 2000. doi:10.2514/6.2000-5586.

[10] Shoji, H., Minegishi, M., and Aoki, T., "Impact characteristics estimation of channel section short column under axial impact load," Structural Dynamics and Materials Conference, Vol. 4, 2007, pp. 3967-3976. doi:10.2514/6.2007-2023.

[11] Kindervater, C. M., Johnson, A. F., Kohlgrüber, D., Lützenburger, M., and Pentecote, N., "Crash and impact simulation of aircraft structures-hybrid and FE based approaches," European congress on computational methods in applied sciences and engineering. Barcelona, Spain: ECCOMAS, 2000.

[12] Jia, X., Chen, G., Yu, Y., Li, G., Zhu, J., Luo, X., Duan, C., Yang, X., and Hui, D., "Effect of geometric factor, winding angle and pre-crack angle on quasi-static crushing behavior of filament wound CFRP cylinder," Composites Part B: Engineering, Vol. 45, No. 1, 2013, pp. 1336-1343. doi:10.1016/j.compositesb.2012.09.060.

[13] Paz, J., Romera, L., and Diaz, J., "Crashworthiness optimization of aircraft hybrid energy absorbers enclosing honeycomb and foam structures," AIAA Journal, Vol. 55, No. 2, 2017, pp. 652-661. doi:10.2514/1.J055245.

[14] Ren, Y., and Xiang, J., "The crashworthiness of civil aircraft using different quadrangular tubes as cabin-floor struts," International Journal of Crashworthiness, Vol. 16, No. 3, 2011, pp. 253-262. doi:10.1080/13588265.2011.554204.

[15] Paz, J., Romera, L., Diaz, J., and Teixeira-Dias, F., "Crashworthiness study on hybrid energy absorbers as vertical struts in civil aircraft fuselage designs," Structural and Multidisciplinary Optimization. Under review, 2018.

[16] Zou, T., Mou, H., and Feng, Z., "Research on Effects of Oblique Struts on Crashworthiness of Composite Fuselage Sections," Journal of Aircraft, Vol. 49, No. 6, 2012, pp. 2059-2063. doi:10.2514/1.c031867. 
[17] Costas, M., Díaz, J., Romera, L., Hernández, S., and Tielas, A., "Static and dynamic axial crushing analysis of car frontal impact hybrid absorbers," International Journal of Impact Engineering, Vol. 62, 2013, pp. 166-181. doi:10.1016/j.ijimpeng. 2013.06.011.

[18] Santosa, S., and Wierzbicki, T., "Crash behavior of box columns filled with aluminum honeycomb or foam," Computers \& Structures, Vol. 68, No. 4, 1998, pp. 343-367. doi:10.1016/s0045-7949(98)00067-4.

[19] Paz, J., Díaz, J., Romera, L., and Costas, M., "Crushing analysis and multi-objective crashworthiness optimization of GFRP honeycomb-filled energy absorption devices," Finite Elements in Analysis and Design, Vol. 91, 2014 , pp. 30-39. doi:10.1016/j.finel.2014.07.006.

[20] Bisagni, C., "Crashworthiness of helicopter subfloor structures," International Journal of Impact Engineering, Vol. 27, No. 10, 2002, pp. 1067-1082. doi:10.1016/s0734-743x(02)00015-5.

[21] Jackson, K. E., Boitnott, R. L., Fasanella, E. L., Jones, L. E., and Lyle, K. H., "A history of full-scale aircraft and rotorcraft crash testing and simulation at NASA Langley Research Center,” 2004.

[22] Hughes, K., and Campbell, J., "Helicopter Crashworthiness: A Chronological Review of Research Related to Water Impact From 1982 to 2006," Journal of the American Helicopter Society, Vol. 53, No. 4, 2008, pp. 429-441. doi:10.4050/jahs.53.429.

[23] Chandra, C., Wong, T., and Bayandor, J., "Crashworthiness assessment in aircraft ditching incidents," 27th International Congress of the Aeronautical Sciences, Nice, France, 2011.

[24] Tay, Y. Y., Bhonge, P. S., and Lankarani, H. M., "Crash simulations of aircraft fuselage section in water impact and comparison with solid surface impact," International journal of crashworthiness, Vol. 20, No. 5, 2015, pp. 464-482. doi:10.1080/13588265.2015.1033972.

[25] Gingold, R. A., and Monaghan, J. J., "Smoothed particle hydrodynamics: theory and application to non-spherical stars," Monthly notices of the royal astronomical society, Vol. 181, No. 3, 1977, pp. 375-389. doi:10.1093/mnras/181.3.375.

[26] Fasanella, E. L., Jackson, K. E., Lyle, K. H., Sparks, C. E., and Sareen, A. K., "Multi-terrain impact tests and simulations of an energy absorbing fuselage section,” Journal of the American Helicopter Society, Vol. 52, No. 2, 2007. doi:10.4050/jahs.52.159.

[27] Fasanella, E. L., and Jackson, K. E., "Crash simulation of vertical drop tests of two Boeing 737 fuselage sections," U.S. Army Research Laboratory, Vehicle Technology Center, Langley Research Center, 2002.

[28] Abromowitz, A., Smith, T. G., and Vu, T., "Vertical drop test of a narrow-body transport fuselage section with a conformable auxiliary fuel tank onboard," 2000., 2000.

[29] Costas, M., Morin, D., Langseth, M., Romera, L., and Díaz, J., “Axial crushing of aluminum extrusions filled with PET foam and GFRP. An experimental investigation,” Thin-Walled Structures, Vol. 99, 2016, pp. 45-57. doi:10.1016/j.tws.2015.11.003.

[30] Boeing Commercial Airplanes, 737 Airplane Characteristics for Airport Planning. D6-58325-6, 2013. 
[31] Cook, G. R., and Johson, W. H., "A constitutive model and data for metals subjected to large strains, high strain rates and high temperatures," Proceedings of Seventh International Symposium on Ballistics, 1983.

[32] Deshpande, V., and Fleck, N., "Isotropic constitutive models for metallic foams," Journal of the Mechanics and Physics of Solids, Vol. 48, No. 6, 2000, pp. 1253-1283. doi:10.1016/s0022-5096(99)00082-4.

[33] Mie, G., “Zur kinetischen Theorie der einatomigen Körper,” Annalen der Physik, Vol. 316, No. 8, 1903 , pp. 657-697. doi:10.1002/andp.19033160802.

[34] Grüneisen, E., “Theorie des festen Zustandes einatomiger Elemente,” Annalen der Physik, Vol. 344, No. 12, 1912 , pp. $257-306$. doi:10.1002/andp.19123441202.

[35] Courchinoux, R., and Lalle, P., "Dynamic properties of water: sound velocity and refractive index," AIP Conference Proceedings, Vol. 370, American Institute of Physics, 1996, pp. 61-64. doi:10.1063/1.50636.

[36] ABAQUS 6.16 Documentation, Dassault Systèmes, 2016.

[37] Eiband, A. M., "Human tolerance to rapidly applied accelerations: a summary of the literature," National Aeronautics and Space Administration (NASA), 1959. 